\title{
Characterization of simultaneous uptake of xylose and glucose in Caldicellulosiruptor kronotskyensis for optimal hydrogen production
}

\author{
Thitiwut Vongkampang ${ }^{1 *}$ (D) , Krishnan Sreenivas ${ }^{1}$, Jonathan Engvall ${ }^{1}$, Carl Grey ${ }^{2}$ and Ed W. J. van Niel ${ }^{1}$
}

\begin{abstract}
Background: Caldicellulosiruptor kronotskyensis has gained interest for its ability to grow on various lignocellulosic biomass. The aim of this study was to investigate the growth profiles of C. kronotskyensis in the presence of mixtures of glucose-xylose. Recently, we characterized a diauxic-like pattern for C. saccharolyticus on lignocellulosic sugar mixtures. In this study, we aimed to investigate further whether C. kronotskyensis has adapted to uptake glucose in the disaccharide form (cellobiose) rather than the monosaccharide (glucose).

Results: Interestingly, growth of C. kronotskyensis on glucose and xylose mixtures did not display diauxic-like growth patterns. Closer investigation revealed that, in contrast to C. saccharolyticus, C. kronotskyensis does not possess a second uptake system for glucose. Both C. saccharolyticus and C. kronotskyensis share the characteristics of preferring xylose over glucose. Growth on xylose was twice as fast $\left(\mu_{\max }=0.57 \mathrm{~h}^{-1}\right)$ as on glucose $\left(\mu_{\max }=0.28 \mathrm{~h}^{-1}\right)$. A study of the sugar uptake was made with different glucose-xylose ratios to find a kinetic relationship between the two sugars for transport into the cell. High concentrations of glucose inhibited xylose uptake and vice versa. The inhibition constants were estimated to be $K_{1, g \mid u}=0.01 \mathrm{cmol} \mathrm{L}^{-1}$ and $K_{1, x y l}=0.001 \mathrm{cmol} \mathrm{L}^{-1}$, hence glucose uptake was more severely inhibited by xylose uptake. Bioinformatics analysis could not exclude that $C$. kronotskyensis possesses more than one transporter for glucose. As a next step it was investigated whether glucose uptake by C. kronotskyensis improved in the form of cellobiose. Indeed, cellobiose is taken up faster than glucose; nevertheless, the growth rate on each sugar remained similar.
\end{abstract}

Conclusions: C. kronotskyensis possesses a xylose transporter that might take up glucose at an inferior rate even in the absence of xylose. Alternatively, glucose can be taken up in the form of cellobiose, but growth performance is still inferior to growth on xylose. Therefore, we propose that the catabolism of $C$. kronotskyensis has adapted more strongly to pentose rather than hexose, thereby having obtained a specific survival edge in thermophilic lignocellulosic degradation communities.

Keywords: Caldicellulosiruptor kronotskyensis, Non-diauxic, Xylose uptake, Glucose uptake, Cellobiose uptake

*Correspondence: thitiwut.vongkampang@tmb.Ith.se

${ }^{1}$ Division of Applied Microbiology, Lund University, P.O. Box 124, 221 00 Lund, Sweden

Full list of author information is available at the end of the article

\section{Background}

Our reliance on fossil fuels resulted in massive greenhouse gases (GHGs) being released into the atmosphere. Biofuels, as an alternative, may contribute to the reduction of $\mathrm{CO}_{2}$ emissions, helping to keep the Paris Agreement that was determined to keep the global temperature below $2{ }^{\circ} \mathrm{C}$ above the pre-industrial level [1]. Of the biofuels, biohydrogen is an interesting energy carrier due to

(c) The Author(s) 2021. This article is licensed under a Creative Commons Attribution 4.0 International License, which permits use, sharing, adaptation, distribution and reproduction in any medium or format, as long as you give appropriate credit to the original author(s) and the source, provide a link to the Creative Commons licence, and indicate if changes were made. The images or other third party material in this article are included in the article's Creative Commons licence, unless indicated otherwise in a credit line to the material. If material is not included in the article's Creative Commons licence and your intended use is not permitted by statutory regulation or exceeds the permitted use, you will need to obtain permission directly from the copyright holder. To view a copy of this licence, visit http://creativeco mmons.org/licenses/by/4.0/. The Creative Commons Public Domain Dedication waiver (http://creativecommons.org/publicdomain/ zero/1.0/) applies to the data made available in this article, unless otherwise stated in a credit line to the data. 
that it does not emit carbon dioxide during combustion. In addition, hydrogen has a gravimetric energy content approximately of $122 \mathrm{~kJ} \cdot \mathrm{g}^{-1}$, which is threefold higher than carbon-based fuels [2].

Strictly anaerobic thermophilic bacteria of the genus of Caldicellulosiruptor are promising for biohydrogen production [3]. These Gram-positive bacteria grow optimally at a temperature of $70-75{ }^{\circ} \mathrm{C}$. The most interesting feature is their ability to grow on a broad-spectrum of substrates, including poly-, oligo-, di- and, monosaccharides [4]. Among these Caldicellulosiruptor species, C. saccharolyticus is the most studied so far, including its physiology related to the sugar transporters [5]. C. saccharolyticus was isolated from thermal springs in New Zealand [6] and its completed genomic sequence has been annotated for its metabolism and transporter systems [7]. More recently, the whole genome of C. saccharolyticus was reannotated to improve the prediction of coding sequences [8]. C. saccharolyticus has been especially studied for its performance on sugar mixtures in lignocellulosic hydrolysates [9-11]. Interestingly, a recent study revealed that $C$. saccharolyticus displayed diauxiclike growth patterns on xylose-glucose mixtures [11].

In 2008, Caldicellulosiruptor kronotskyensis was isolated from thermal springs in Kamchatka, Russia. This species was considered akin to C. saccharolyticus and other species in the genus of Caldicellulosiruptor, with genome similarity levels between 94.8-97.7\% [12], but the physiology of $C$. kronotskyensis has hardly been studied. During recent years, C. kronotskyensis has gained more interest due to its tāpirin proteins that attach to lignocellulosic materials [13] and it is well equipped for the breakdown of lignocellulosic biomass [14]. In addition, C. kronotskyensis was studied for its xylanase [15, 16], pectate lyase for the deconstruction of plant biomass [17] and has been used to enhance polyhydroxybutyrate (PHB) formation in a sequential fermentation [18]. Therefore, C. kronotskyensis is a potential platform for the production of biofuels and valuable chemicals.

Cellulose and hemicellulose are the major constituents of lignocellulosic biomass. Cellulose is a linear polymer consisting of glucose units linked by $\beta$-1,4-glycosidic bonds [19]. The hydrolysis of cellulose typically produces cellobiose and other oligomers. Hemicellulose is a heteropolymer with a side chain that comprises pentoses and hexoses, i.e., xylose, glucose, mannose, and other derivatives [20].

The current study focused on the physiology of C. kronotskyensis growing on mixtures of xylose and glucose such as in lignocellulosic hydrolysates. The growth profiles of C. kronotskyensis were evaluated against those of C. saccharolyticus in a former study [11]. Due to a difference in the growth pattern between these two species, the uptake of xylose and glucose in C. kronotskyensis was studied in further detail, which included also cellobiose as an alternative source of glucose. The generated data revealed that $C$. kronotskyensis might have adapted to xylose-based metabolism and takes up glucose preferentially, in the form of cellobiose and possibly other oligosaccharides, which may pinpoint its micro-niche in lignocellulosic degradation in its natural environment.

\section{Results}

\section{Growth profiles on the single sugar}

Batch cultivations of C. kronotskyensis on $10 \mathrm{~g} \cdot \mathrm{L}^{-1}$ of xylose (Case A), $10 \mathrm{~g} \cdot \mathrm{L}^{-1}$ of glucose (Case B), and $10 \mathrm{~g} \cdot \mathrm{L}^{-1}$ of cellobiose (Case C) were performed in a CSTR to monitor substrate utilization, biomass, and products formation. C. kronotskyensis assimilated xylose and cellobiose faster than glucose (Fig. 1a). However, there was no difference in biomass and acetate production during the fermentation of each sugar. For the fermentation on xylose, lactate production was twice and thrice higher than for the fermentation on cellobiose and glucose, respectively (Fig. 1b-d).

\section{Xylose-glucose uptake competition}

C. kronotskyensis was cultivated in media containing xylose and glucose mixtures with different ratios (Table 1, Cases D-F). The results of Case D and Case E revealed that xylose was consumed from the early logarithmic phase until the stationary phase. On the other hand, C. kronotskyensis did hardly take up glucose when the amount of xylose was higher than $0.1 \mathrm{cmol} \cdot \mathrm{L}^{-1}$ (Fig. 2a, b). Moreover, the uptake of glucose (Case E) began only after the level of xylose became below $0.05 \mathrm{cmol} \cdot \mathrm{L}^{-1}$ (Fig. 2b). This phenomenon was also observed in Case $\mathrm{F}$ (Fig. 2c) and Case G (Fig. 3a). Cultures containing higher concentrations of xylose in the sugar mixtures produced more lactate, i.e., lactate formation in Case D and Case E were approximately thrice and a half higher, respectively, than in Case F (Fig. 2). However, there was no difference in acetate production and biomass formation among these three cases.

\section{Growth profiles on the mixed sugars}

In Case G, xylose depleted earlier than glucose. Subsequently, glucose was not taken up faster as was expected but continued at a constant speed (Fig. 3a). For Case H, glucose was substituted by cellobiose, which resulted in that both sugars were concurrently consumed (Fig. 3b). Surprisingly, the total fermentation period (Case H) was approximately half the time shorter comparing to the other two cases where glucose was presented (Cases G and I). For Case I (Fig. 3c), the uptake profile of cellobiose was similar to that of the xylose uptake profile in Case G 

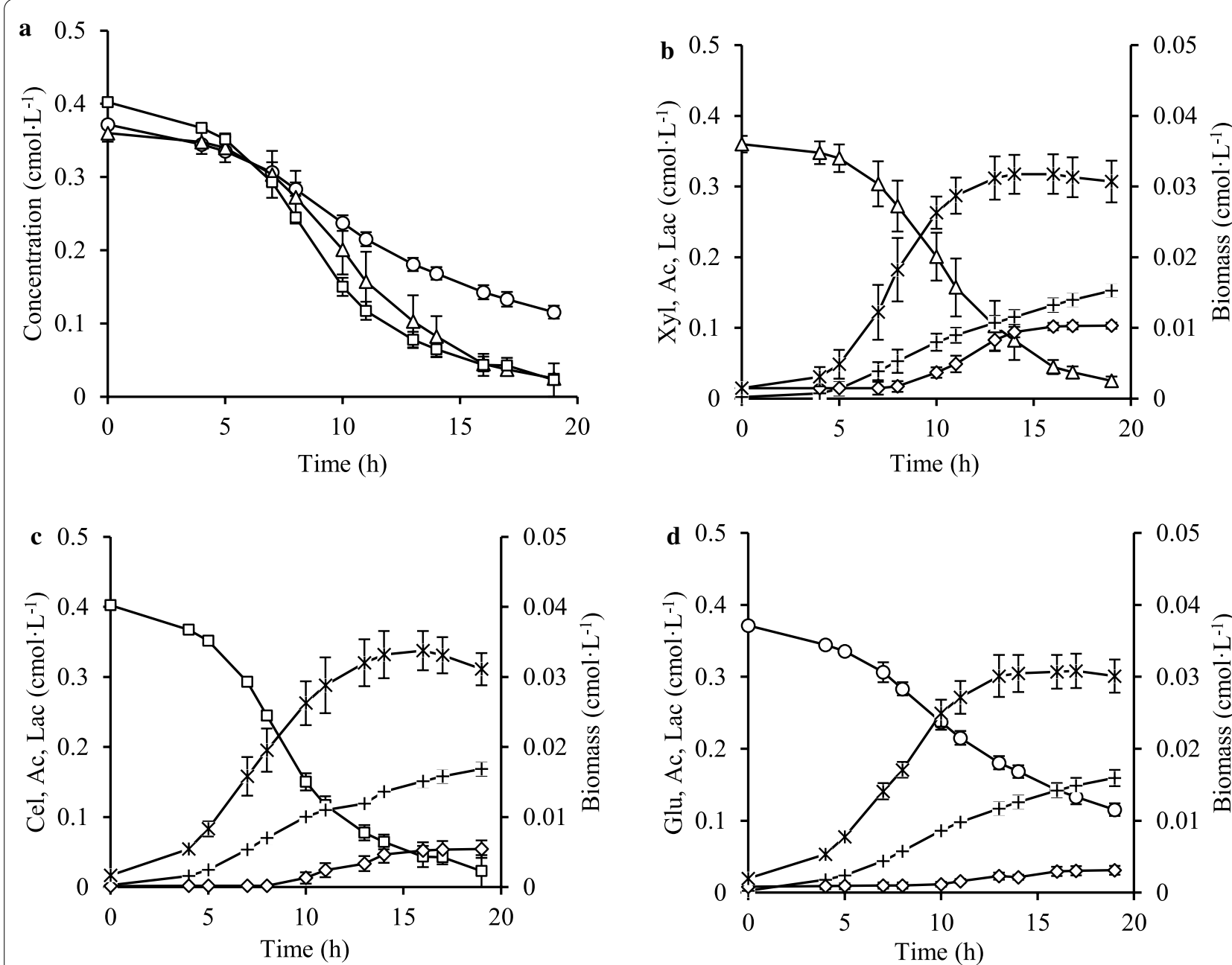

Fig. 1 Growth pattern, sugar consumption and products formation on single sugar: a summary of sugar uptake profiles; $\mathbf{b}$ growth of $C$. kronotskyensis on $10 \mathrm{~g} \cdot \mathrm{L}^{-1}$ xylose (Case A); c growth of C. kronotskyensis on $10 \mathrm{~g} \cdot \mathrm{L}^{-1}$ cellobiose (Case B); $\mathbf{d}$ growth of C. kronotskyensis on $10 \mathrm{~g} \cdot \mathrm{L}^{-1}$ glucose (Case C). (Open triangle) xylose (Xyl); (open square) cellobiose (Cel); (open circle) glucose (Glu); (multiplication) biomass; (open diamond) lactate (Lac); ( plus) acetate (Ac).

Table 1 Fermentation conditions performed in this study

\begin{tabular}{ll}
\hline Name & Cultivation conditions \\
\hline Case A & $10 \mathrm{~g} \cdot \mathrm{L}^{-1}$ xylose \\
Case B & $10 \mathrm{~g} \cdot \mathrm{L}^{-1}$ cellobiose \\
Case $C$ & $10 \mathrm{~g} \cdot \mathrm{L}^{-1}$ glucose \\
Case D & $2 \mathrm{~g} \cdot \mathrm{L}^{-1}$ glucose and $12 \mathrm{~g} \cdot \mathrm{L}^{-1}$ xylose \\
Case E & $3 \mathrm{~g} \cdot \mathrm{L}^{-1}$ glucose and $9 \mathrm{~g} \cdot \mathrm{L}^{-1}$ xylose \\
Case F & $9 \mathrm{~g} \cdot \mathrm{L}^{-1}$ glucose and $3 \mathrm{~g} \cdot \mathrm{L}^{-1}$ xylose \\
Case $\mathrm{G}$ & $7.3 \mathrm{~g} \cdot \mathrm{L}^{-1}$ glucose and $3.4 \mathrm{~g} \cdot \mathrm{L}^{-1}$ xylose \\
Case $\mathrm{H}$ & $7.3 \mathrm{~g} \cdot \mathrm{L}^{-1}$ cellobiose and $3.4 \mathrm{~g} \cdot \mathrm{L}^{-1}$ xylose \\
Case I & $5 \mathrm{~g} \cdot \mathrm{L}^{-1}$ cellobiose and $5 \mathrm{~g} \cdot \mathrm{L}^{-1} \mathrm{glucose}$ \\
\hline
\end{tabular}

and Case $\mathrm{H}$, but the uptake profile of glucose was quite similar to the glucose profile in Case G.

Acetate was the main soluble by-product obtained from the growth profiles during the fermentation of mixed sugars. Acetate formation in Case G was approximately 1.5-fold higher than the acetate level in both Case $\mathrm{H}$ and Case I. Lactate in Case $\mathrm{H}$ was approximately 1.5 times higher than in Case I and just about fivefold higher than in Case G. Biomass observed in Case I was $0.035 \mathrm{cmol} \cdot \mathrm{L}^{-1}$, which was one and a halffold greater than Case $\mathrm{H}\left(0.026 \mathrm{cmol} \cdot \mathrm{L}^{-1}\right)$ and almost twice higher for Case $\mathrm{G}\left(0.018 \mathrm{cmol} \cdot \mathrm{L}^{-1}\right)$ (Fig. 3a-c). Neither of the monitored profiles of $\mathrm{Q}_{\mathrm{H} 2}$ and $\mathrm{Q}_{\mathrm{CO} 2}$ during the fermentation of mixed sugars displayed any 

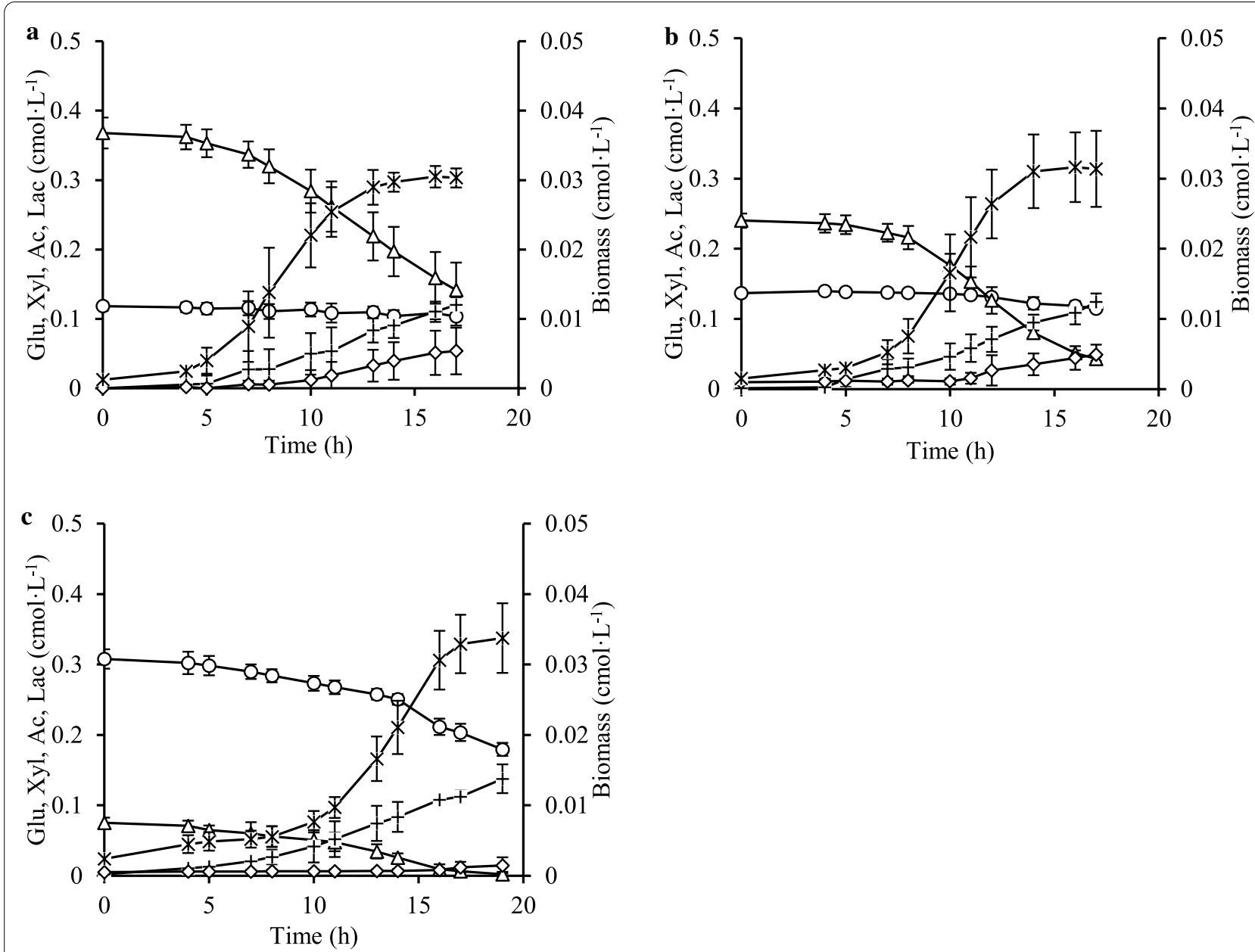

Fig. 2 Growth pattern, sugar consumption and products formation for xylose-glucose competition: a growth of C. kronotskyensis on $12 \mathrm{~g} \cdot \mathrm{L}^{-1}$ xylose and $2 \mathrm{~g} \cdot \mathrm{L}^{-1}$ glucose (Case D); $\mathbf{b}$ growth of $C$. kronotskyensis on $9 \mathrm{~g} \cdot \mathrm{L}^{-1}$ xylose and $3 \mathrm{~g} \cdot \mathrm{L}^{-1}$ glucose (Case E); $\mathbf{c}$ growth of $C$. kronotskyensis on $3 \mathrm{~g} \cdot \mathrm{L}^{-1}$ xylose and $9 \mathrm{~g} \cdot \mathrm{L}^{-1}$ glucose (Case F). (Open triangle) xylose (Xyl); (open circle) glucose (Glu); ( multiplication) biomass; (open diamond) lactate (Lac); ( plus) acetate (Ac).

diauxic-like growth patterns (Fig. 4a, b), as it has been observed for C. saccharolyticus [11].

\section{Estimation of $\mu_{\max }$ from the fermentations on single sugar} The $\mu_{\max }$ of the culture of C. kronotskyensis on xylose (Case A) was $0.57 \mathrm{~h}^{-1}$, which was nearly twice higher than the $\mu_{\max }$ of the culture on cellobiose (Case B) and glucose (Case C) (Table 2). For the xylose-glucose competition, the $\mu_{\max }$ was higher at higher xylose/glucose ratio (Cases D and E) than at a lower ratio. With a mixture of cellobiose and xylose $($ Case $\mathrm{H})$, the culture reached a $\mu_{\max }$ between the $\mu_{\max }$ of each sugar alone and was significantly higher than for the mixture of xylose-glucose (Case G) and cellobiose-glucose (Case I).
Determination of yields, carbon balance and redox balance In this study, the carbon balance indicated good carbon recovery, and, all redox balance represented above 95\%, denoting reliable $\mathrm{H}_{2}$ measurements. Yields were calculated by using the overall product formed divided by the total substrate converted. For single sugar, the yield of hydrogen $\left(Y_{\mathrm{SH}}\right)$, carbon dioxide $\left(Y_{\mathrm{SC}}\right)$, and acetate $\left(Y_{\mathrm{SA}}\right)$ for glucose alone (Case $C$ ) were higher than for xylose (Case A) and cellobiose (Case B). In contrast, the yield of lactate $\left(Y_{\mathrm{SL}}\right)$ for Case A was greater than Case B and Case C. Moreover, the yield of biomass $\left(Y_{\mathrm{SX}}\right)$ of these cases (Cases A-C) was at a similar level (Table 2).

The yield of hydrogen $\left(Y_{\mathrm{SH}}\right)$, carbon dioxide $\left(Y_{\mathrm{SC}}\right)$, and acetate $\left(Y_{\mathrm{SA}}\right)$ for the different xylose-glucose ratios (Cases D-F) were overall quite similar. Except for the yield of lactate $\left(Y_{\mathrm{SL}}\right)$ for Case $\mathrm{F}$ was slightly lower than for Case D and Case E. The highest yield of biomass 

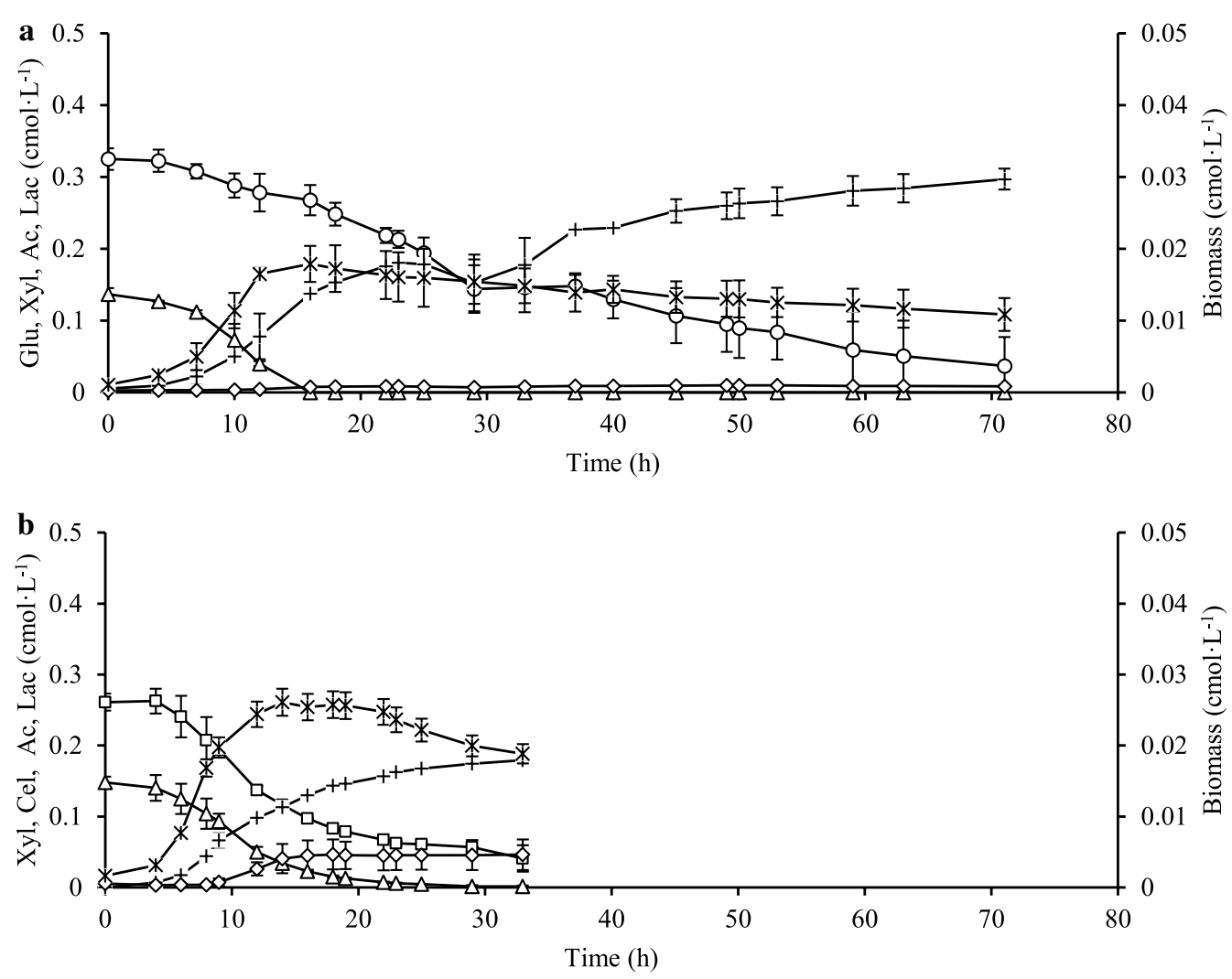

c

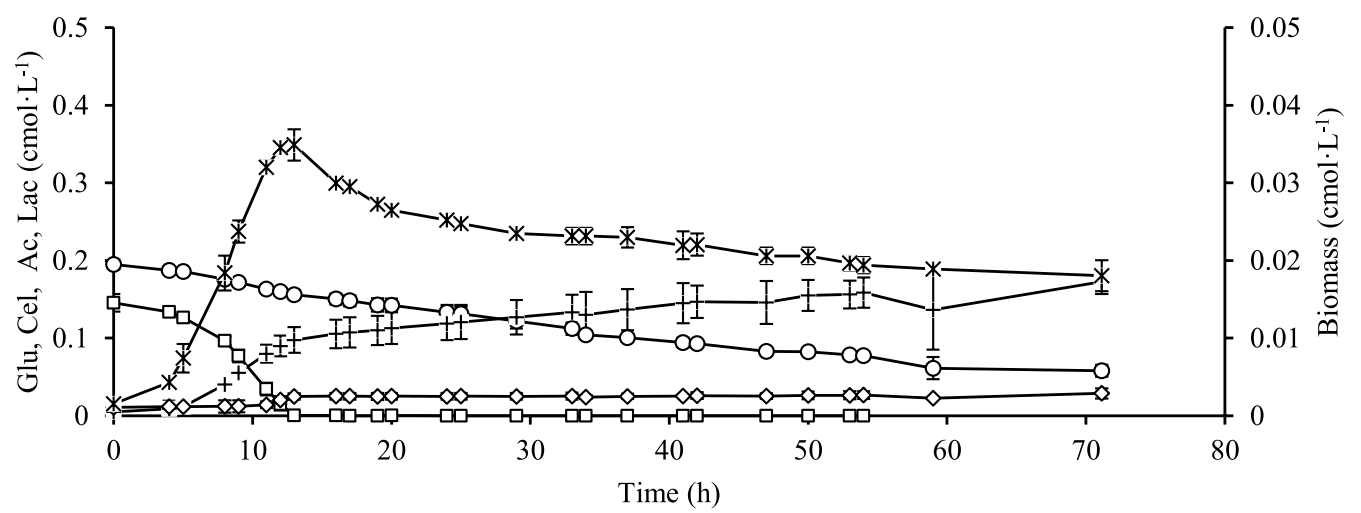

Fig. 3 Growth pattern, sugar consumption and products formation on mixed sugars: a growth of C. kronotskyensis on $3.4 \mathrm{~g} \cdot \mathrm{L}^{-1} \mathrm{xylose}$ and $7.3 \mathrm{~g} \cdot \mathrm{L}^{-1}$ glucose (Case D); b growth of C. kronotskyensis on $3.4 \mathrm{~g} \cdot \mathrm{L}^{-1}$ xylose and $7.3 \mathrm{~g} \cdot \mathrm{L}^{-1}$ cellobiose (Case E); c growth of C. kronotskyensis on $5 \mathrm{~g} \cdot \mathrm{L}^{-1} \mathrm{glucose}$ and $5 \mathrm{~g} \cdot \mathrm{L}^{-1}$ cellobiose (Case F). (Open triangle) xylose (Xyl); (open circle) glucose (Glu); (open square) cellobiose (Cel); (multiplication) biomass; (open diamond) lactate (Lac); (plus) acetate (Ac).

$\left(Y_{\mathrm{SX}}\right)$ was in Case $\mathrm{E}$, followed by the $Y_{\mathrm{SX}}$ in Case $\mathrm{F}$, which was similar to the $Y_{\mathrm{SX}}$ in Case D (Table 2).

For the cultivation of the mixed sugars, the yield of hydrogen $\left(Y_{\mathrm{SH}}\right)$, carbon dioxide $\left(Y_{\mathrm{SC}}\right)$, and acetate $\left(Y_{S A}\right)$ in Case $\mathrm{H}$ and Case I were similar, but both were significantly higher than Case G. However, the yield of lactate $\left(Y_{\mathrm{SL}}\right)$ in Case $\mathrm{H}$ was lower than Case $\mathrm{G}$ and Case I.
Furthermore, Case I showed a higher yield of biomass $\left(Y_{\mathrm{SH}}\right)$ than Case $\mathrm{G}$ and Case $\mathrm{H}$.

\section{Specific substrate consumption rate (qS) and specific $\mathrm{H}_{2}$ production rate $\left(\mathrm{qH}_{2}\right)$}

The specific substrate consumption (qS) on single sugar and mixed sugars were calculated based on substrate in 


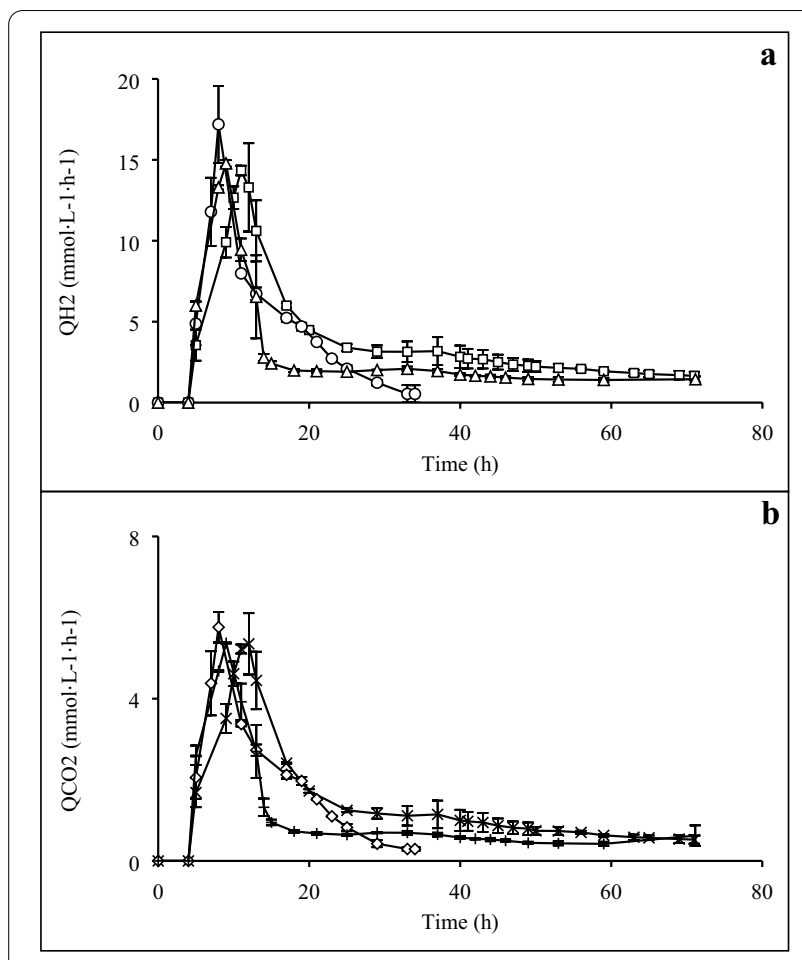

Fig. 4 Volumetric hydrogen productivity $\left(\mathrm{Q}_{\mathrm{H} 2}\right)$ and volumetric carbon dioxide productivity $\left(\mathrm{Q}_{\mathrm{CO} 2}\right) \cdot \mathbf{a} \mathrm{Q}_{\mathrm{H} 2}$ obtained in Case $\mathrm{G}$ (open square), Case $\mathrm{H}$ (open circle), and Case I (open triangle); $\boldsymbol{b} \mathrm{Q}_{\mathrm{CO} 2}$ obtained in Case G (multiplication), Case H (open diamond), and Case I ( plus)

$\mathrm{cmol} \cdot \mathrm{L}^{-1} \cdot \mathrm{h}^{-1}$ divided by cell dry weight $\left(\mathrm{gCDW} \cdot \mathrm{L}^{-1}\right)$. The specific $\mathrm{H}_{2}$ production $\left(\mathrm{qH}_{2}\right)$ of each fermentation was calculated from the volumetric hydrogen productivity $\left(\mathrm{Q}_{\mathrm{H} 2}, \mathrm{mmol} \cdot \mathrm{L}^{-1} \cdot \mathrm{h}^{-1}\right)$ divided by cell dry weight $\left(\mathrm{gCDW} \cdot \mathrm{L}^{-1}\right)$. For Case A, the specific xylose consumption (qXyl) was approximately $0.67 \mathrm{cmol} \cdot \mathrm{gCDW}^{-1} \cdot \mathrm{h}^{-1}$, whereas the specific glucose consumption (qGlu) in
Case $\mathrm{C}$ was $0.44 \mathrm{cmol} \cdot \mathrm{gCDW}^{-1} \cdot \mathrm{h}^{-1}$ (Fig. 5a). During the fermentation with different xylose-glucose mixtures, qXyl decreased with decreasing xylose/glucose ratios. A similar phenomenon also occurred in case of qGlu, which decreased with increasing xylose/glucose ratios. It is worth noting that the $\mathrm{qH}_{2}$ of culture fermenting xylose was significantly decreased from 13 to $6.8 \mathrm{mmol} \cdot \mathrm{gCDW}^{-1} \cdot \mathrm{h}^{-1}$ when glucose was present. For the mixture of xylose and cellobiose (Case $H)$, the specific cellobiose consumption (qCel) was lower than both qXyl and qGlu (Fig. 5b). Interestingly, qCel increased dramatically from 0.25 to $0.7 \mathrm{cmol} \cdot \mathrm{gCDW}^{-1} \cdot \mathrm{h}^{-1}$ in the case of xylose-cellobiose mixture (Case $\mathrm{H})$ while qXyl showed no significant decrease. The $\mathrm{qH}_{2}$ of Case $\mathrm{H}$ improved somewhat when compared with $\mathrm{qH}_{2}$ of Case $\mathrm{B}$. For Case I, only qGlu considerably decreased from 0.44 to $0.15 \mathrm{cmol} \cdot \mathrm{gCDW}^{-1} \cdot \mathrm{h}^{-1}$, whereas qCel did not show any remarkably change (Fig. $5 \mathrm{c}$ ). Moreover, there were no differences between the $\mathrm{qH}_{2}$ obtained in Case $\mathrm{B}$, Case $\mathrm{C}$, and Case I.

\section{Inhibition kinetics of xylose and glucose uptake}

As Fig. 5a depicts, the specific consumption rate of both xylose and glucose declined in the sugar mixture when more of the other sugar was present. This indicated competitive inhibition and, therefore, the inhibition constant $\left(K_{I}\right)$ for xylose $\left(K_{\mathrm{I}, \mathrm{xyl}}\right)$ and glucose $\left(K_{\mathrm{I}, \mathrm{glu}}\right)$ were estimated (Eqs. 3,4) focusing only on the cases of the xylose-glucose mixture (Cases D-G). It was found that the $K_{\mathrm{I}, \mathrm{glu}}$ was $0.01 \mathrm{cmol} \cdot \mathrm{L}^{-1}$, being ten times higher than $K_{\mathrm{I}, \mathrm{xyl}}$ $\left(0.001 \mathrm{cmol} \cdot \mathrm{L}^{-1}\right)$, or glucose uptake was more severely inhibited by xylose than vice versa.

\section{Competitive of sugar uptake in C. kronotskyensis}

The sugars in Case G, Case H, and Case I were plotted to exhibit the relative stoichiometry of each sugar uptake

Table 2 Calculated yields, carbon balance, redox balance, and $\mu_{\max }$ of the fermentations in this study

\begin{tabular}{|c|c|c|c|c|c|c|c|c|}
\hline \multirow[t]{3}{*}{ Sugar } & \multicolumn{5}{|l|}{ Yield } & \multirow[t]{3}{*}{ Carbon balance } & \multirow[t]{3}{*}{ Redox balance } & \multirow[t]{3}{*}{$\mu_{\max }\left(\mathrm{h}^{-1}\right)$} \\
\hline & $Y_{S H}$ & $Y_{S C}$ & $Y_{S A}$ & $Y_{S L}$ & $Y_{S X}$ & & & \\
\hline & \multicolumn{2}{|l|}{$\left[\mathrm{mol} \cdot \mathrm{cmol}^{-1}\right]$} & \multicolumn{3}{|l|}{$\left[\mathrm{cmol} \cdot \mathrm{cmol}^{-1}\right]$} & & & \\
\hline Case A & $0.36 \pm 0.02$ & $0.14 \pm 0.01$ & $0.46 \pm 0.02$ & $0.26 \pm 0.04$ & $0.19 \pm 0.02$ & $1.03 \pm 0.03$ & $1.05 \pm 0.04$ & 0.57 \\
\hline Case B & $0.35 \pm 0.05$ & $0.14 \pm 0.02$ & $0.45 \pm 0.05$ & $0.14 \pm 0.01$ & $0.15 \pm 0.01$ & $1.08 \pm 0$ & $1.09 \pm 0$ & 0.30 \\
\hline Case C & $0.50 \pm 0.02$ & $0.20 \pm 0.01$ & $0.61 \pm 0.02$ & $0.09 \pm 0.04$ & $0.17 \pm 0.01$ & $1.04 \pm 0.02$ & $1.06 \pm 0.03$ & 0.28 \\
\hline Case D & $0.42 \pm 0.08$ & $0.16 \pm 0.03$ & $0.52 \pm 0.10$ & $0.22 \pm 0.11$ & $0.09 \pm 0.06$ & $1.07 \pm 0.02$ & $1.03 \pm 0.02$ & 0.43 \\
\hline Case E & $0.50 \pm 0.01$ & $0.19 \pm 0.01$ & $0.57 \pm 0.08$ & $0.18 \pm 0.06$ & $0.25 \pm 0.08$ & $1.04 \pm 0.07$ & $0.97 \pm 0.04$ & 0.43 \\
\hline Case F & $0.54 \pm 0.03$ & $0.20 \pm 0.01$ & $0.67 \pm 0.13$ & $0.05 \pm 0.05$ & $0.15 \pm 0.07$ & $1.04 \pm 0.06$ & $1.01 \pm 0.03$ & 0.21 \\
\hline Case $\mathrm{G}$ & $0.38 \pm 0.03$ & $0.15 \pm 0.01$ & $0.48 \pm 0.04$ & $0.14 \pm 0.05$ & $0.14 \pm 0.01$ & $1.12 \pm 0.05$ & $1.06 \pm 0.04$ & 0.25 \\
\hline Case $\mathrm{H}$ & $0.54 \pm 0.01$ & $0.21 \pm 0.01$ & $0.70 \pm 0.02$ & $0.02 \pm 0$ & $0.11 \pm 0$ & $1.11 \pm 0.02$ & $1.08 \pm 0.01$ & 0.41 \\
\hline Case I & $0.50 \pm 0.06$ & $0.20 \pm 0.02$ & $0.69 \pm 0.08$ & $0.16 \pm 0.12$ & $0.26 \pm 0.04$ & $0.99 \pm 0.01$ & $0.95 \pm 0.01$ & 0.31 \\
\hline
\end{tabular}




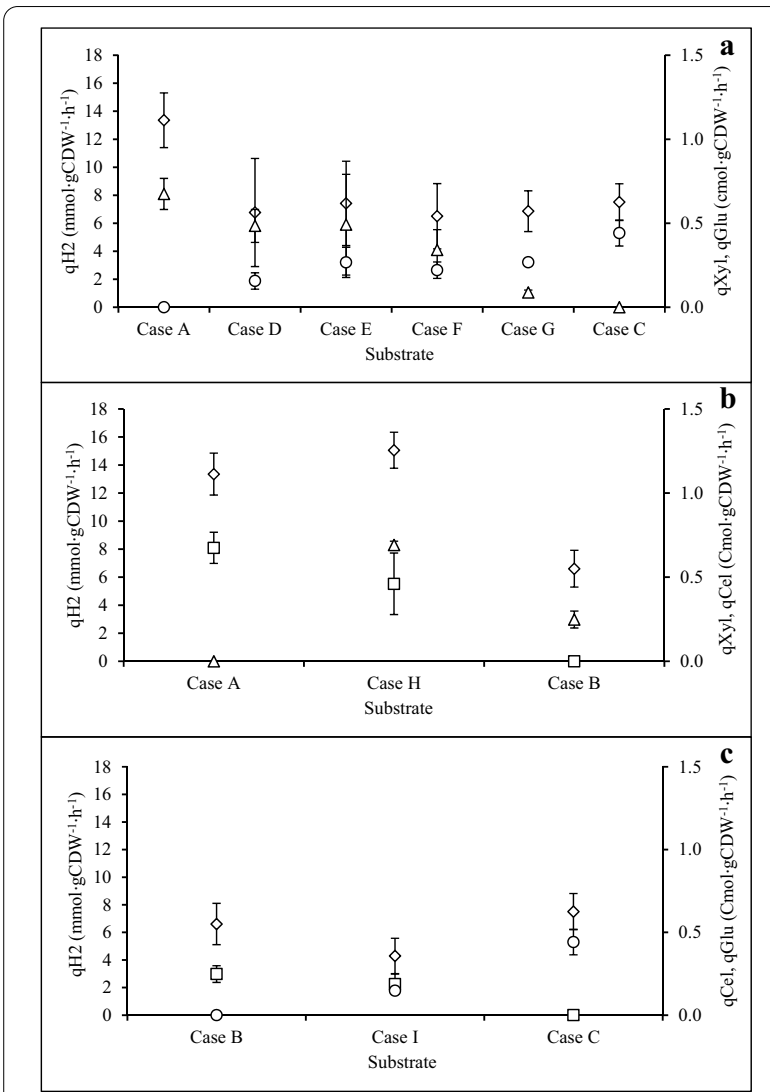

Fig. 5 Specific substrate consumption (qS) and specific hydrogen production $\left(\mathrm{qH}_{2}\right)$. a Specific xylose consumption ( $\mathrm{qXyl}$ ), specific glucose consumption (qGlu), and specific hydrogen production $\left(\mathrm{qH}_{2}\right)$ for Case D, Case E, Case G, and Case F comparing with Case A and Case C. b Specific xylose consumption (qXyl), specific cellobiose consumption (qCel), and specific hydrogen production $\left(\mathrm{qH}_{2}\right)$ for Case $\mathrm{H}$ comparing with Case A and Case B. c Specific xylose consumption (qXyl), specific cellobiose consumption (qCel), and specific hydrogen production $\left(\mathrm{qH}_{2}\right)$ for Case I comparing with Case B and Case C. (Open triangle) qXyl; (open square) qCel; (open circle) qGlu; (open diamond) $\mathrm{qH}_{2}$

during the exponential phase. As depicted in Fig. 6a, the uptake of xylose and glucose (Case G) was seemingly linear depicting a certain metabolic stoichiometry $\left(R^{2}=0.814\right)$.Similarly, sugar uptake of the other two cases (Cases $\mathrm{H}$ and I) was linearly related throughout the cultivation $\left(\mathrm{R}^{2} \geq 0.989\right)$ (Fig. 6b, c) reflecting a more stable stoichiometry than in Case G, which might be related to the use of two separate sugar transporters.

\section{Bioinformatics related on sugar transporters}

Since carbohydrate transporters play a crucial role in sugar uptake during the growth of bacteria, obvious differences in sugar transporters between the already studied C. saccharolyticus [21] and C. kronotskyensis were

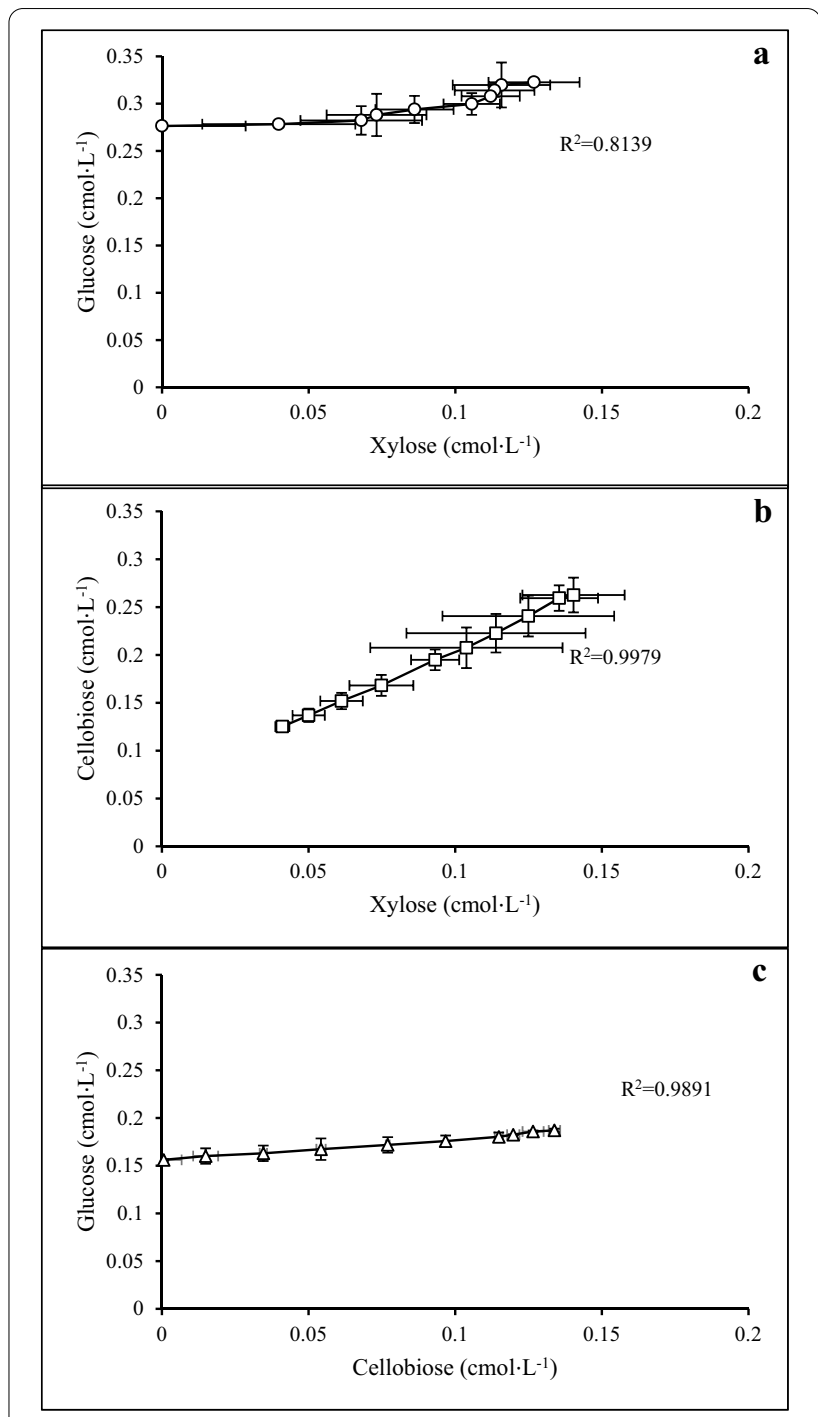

Fig. 6 Stoichiometry of substrate uptake in the cultures on mixed sugars during the logarithmic phase. a Relation between xylose and glucose uptake. b Relation between xylose and cellobiose uptake. $\mathbf{c}$ Relation between cellobiose and glucose uptake. (Open circle) Case $\mathrm{G}$; (open square) Case H; (open triangle) Case I

compared using genome alignment produced by Mauve. Upon analysis of the genome alignment, there were two sugar transporters that were absent in C. kronotskyensis. These sugar transporters belong to the Dpp/Opp family for fructose and sucrose uptake as well as a CUT1 family sugar transporter for xyloglucan (Table 3).

\section{Discussion}

This study was performed after the observation that $C$. kronotskyensis did not possess a diauxic-like growth pattern on xylose-glucose fermentations (Fig. 4) as has been described for C. saccharolyticus in a previous study [11]. 
Both volumetric productivity profiles of hydrogen $\left(\mathrm{Q}_{\mathrm{H} 2}\right)$ and carbon dioxide $\left(\mathrm{Q}_{\mathrm{CO} 2}\right)$ consist of only one peak corresponding to the exponential growth phase. In contrast to C. saccharolyticus, there is no second peak after xylose has been consumed. Instead, $\mathrm{Q}_{\mathrm{H} 2}$ and $\mathrm{Q}_{\mathrm{CO} 2}$ continued to decline even though plenty of glucose was still present. In the presence of xylose in both species a transporter is expressed that takes up both xylose and glucose. The mechanism behind the diauxic-like growth pattern in $C$. saccharolyticus was based on a second transporter for glucose being expressed after depletion of xylose [11]. C. kronotskyensis has a genetic similarity of approximately $94 \%$ with C. saccharolyticus [12], and one of the differences is a lower number of $\mathrm{ABC}$ transporters for sugar uptake in C. kronotskyensis (Table 3). The results obtained in this study indicated that C. kronotskyensis might be missing a second transporter for glucose. Based on this evidence, we studied the simultaneous uptake of glucose and xylose in C. kronotskyensis by means of one transporter using different concentration ratios of xylose and glucose. Like for C. saccharolyticus [11, 21], this transporter has a preference for xylose and at high concentrations of this sugar, whereas glucose is hardly taken up. For obvious reasons, a competitive inhibition was assumed, and the kinetic analysis demonstrated that xylose inhibited glucose uptake more severely than the other way around. The uptake of both sugars simultaneously affected the overall growth rate, but there is no clear indication that it affected the biomass yield and hydrogen yield (Table 2 ).

Due to a low preference for glucose, it could be expected that C. kronotskyensis is taking up this hexose preferably in the form of oligosaccharides. Several oligosaccharide transporters can be assigned in the genome of this species (Table 3), and indeed cellobiose was taken up via a separate transporter in the presence of xylose according to the concentration profiles of the two sugars in Fig. 3b. Both sugars were taken up simultaneously with a stable stoichiometry as demonstrated in Fig. 6b. A similar relationship was observed for the glucose and cellobiose mixture (Fig. 6c). Cellobiose might be taken up through the transporters labelled as Calkro_0108-0110, as being predicted for gluco-oligosaccharides [13]. However, the non-linear correlation between simultaneous uptake of xylose and glucose is connected to the competition taking place at the xylose transporter (Fig. 6a). Curiously, after depletion of cellobiose in Case I, the uptake of glucose continued with the same slow uptake throughout the remainder of the fermentation. The fact that uptake of glucose was linear probably due to that was no further increase of cell mass, which might indicate either limitation of another nutrient or is caused by a yet unknown mechanism. C. saccharolyticus, C. owensensis, and C. kristjanssonii have in common that they prefer xylose over other sugars in mixed substrate cultures. Nonetheless, when these three species were cultivated together, the uptake of glucose and xylose occurred concurrently [22]. This sugar preference pinpoints to an adaptation to a specific niche within the thermophilic lignocellulosic degradation community. Other such specialization within lignocellulosic degradation communities has been indicated before [23].

With xylose, the $\mu_{\max }$ was $0.57 \mathrm{~h}^{-1}$ which is significantly higher than the $\mu_{\max }$ observed for C. saccharolyticus $\left(0.25 \mathrm{~h}^{-1}\right)$ [24] and C. owensensis $\left(0.20 \mathrm{~h}^{-1}\right)$ [25].

Table 3 Comparison of carbohydrate transporters between C. kronotskyensis (the current study) and C. saccharolyticus

\begin{tabular}{llll}
\hline ABC transporter (Csac_) & Group & $\begin{array}{l}\text { ABC transporter } \\
\text { (Calkro_) }\end{array}$ & Features \\
\hline $0238,0240-0242$ & CUT2 & $0382,0384-0386$ & Arabinose, galactose, xylose \\
$0261-0265$ & Dpp/Opp & $0283-0284,0287$ & Fructose, sucrose \\
$0427-0428,0431$ & CUT1 & $2234-2236$ & Maltodextrin \\
$0440-0442$ & CUT1 & $2010-2012$ & Galactose \\
$0692-0694$ & CUT1 & $0798-0802$ & Monosaccharides \\
$1028-1032$ & Dpp/Opp & None & Monosaccharides \\
$1557-1559$ & CUT1 & $0930,0932,0933-0934$ & Xyloglucan \\
$2321-2322,2324,2326$ & CUT1 & $2389-2391$ & Glucose, xylose, fructose \\
$2412-2414$ & CUT1 & $2394-2396$ & Xylooligosaccharides \\
$2417-2419$ & CUT1 & $0321-0323$ & Xylooligosaccharides \\
$2491-2493$ & CUT1 & $0128-0130$ & Xylose, glucose, fructose \\
$2504-2506$ & CUT2 & $0108-0110$ & Xylose, glucose, fructose \\
$2514-2516$ & CUT1 & Glucooligosaccharides
\end{tabular}

The ABC transporters (Csac_), group and features of C. saccharolyticus were taken from a previous study [21] 
In the current study, cellobiose uptake was also superior to that of glucose even though the $\mu_{\max }$ on each of these sugars was quite similar. The $\mu_{\max }$ on glucose obtained by $C$. kronotskyensis $\left(0.28 \mathrm{~h}^{-1}\right)$ was slightly higher than the $\mu_{\max }$ obtained in $C$. saccharolyticus $\left(0.23 \mathrm{~h}^{-1}\right)[11,22]$. In the case of glucose and xylose mixtures, the $\mu_{\max }$ increased with the xylose/glucose ratio as the growth rate was mainly determined by xylose but inhibited by glucose. This phenomenon was further investigated by a competitive kinetic model that indicated that glucose was more severely inhibited by xylose than vice versa. Interestingly, the $\mu_{\max }$ of cultures on xylose and cellobiose mixtures was halfway between the maximum specific growth rates for each case on single sugar (Table 2), which is correlated with a certain conversion stoichiometry between cellobiose and xylose (Fig. 6b).

The qXyl was not significantly different in the presence of cellobiose in the medium. As aforementioned, xylose and cellobiose were consumed concurrently. Interestingly, qCel obtained in Case $\mathrm{H}$ considerably improved almost threefold compared to qCel in Case B (Fig. 5b). Therefore, both qXyl and qCel also confirmed that the assimilation of xylose and cellobiose in C. kronotskyensis occurred with different sugar transporters.

\section{Conclusion}

The current study highlighted the lack of a diauxic-like growth pattern in C. kronotskyensis during fermentation of the xylose-glucose mixture. C. kronotskyensis has the highest preference for xylose and cellobiose compared to glucose. This is exemplified by the lack of a specific glucose transporter and the highest growth rate observed with xylose in single-sugar cultures. Nevertheless, the highest $\mathrm{Q}_{\mathrm{H} 2}$ has been observed in the presence of glucose and/or cellobiose. This study further supports that members of the genus Caldicellulosiruptor have adapted to xylose and disaccharides (cellobiose) rather than glucose as primary substrates, which may give them a competitive edge in thermophilic lignocellulosic degradation. It further shows that C. kronotskyensis is a promising candidate for biohydrogen production from lignocellulosic material.

\section{Materials and methods}

\section{Microorganism and cultivation medium}

Caldicellulosiruptor kronotskyensis DSM 18902 was purchased from the Deutsche Sammlung von Mikroorganismen und Zellkulturen (Braunschweig, Germany). The inoculum was prepared by subculturing routinely in $250-\mathrm{mL}$ serum flasks containing $50 \mathrm{~mL}$ of modified DSM medium 640. The medium composition used in this study was previously described by [25]. The cultivation medium (DSM medium 640) without yeast extract, 1000X vitamin solution, and modified SL-10 solution were prepared according to $[25,26]$.

\section{Experimental design}

The batch cultivations were performed with different sugar ratios (Table 1). Briefly, the control conditions were Cases A, B, and C, which were single-sugar cultivation on xylose, cellobiose, and glucose, respectively. Uptake kinetics on different sugar ratios were performed in Cases D, E, F, and G. The sugar mixtures in Case G were based on the ratio seen in wheat straw hydrolysate [11]. In addition, each of these sugars was combined with cellobiose to determine the preference of sugar uptake (Cases $\mathrm{H}$ and I). All cultivations were done in biological duplicate.

\section{Fermentation setup}

Batch fermentations were performed in a 3-L bioreactor provided with ADI 1025 Bio-console and ADI 1010 Bio-Controller (Applikon, Schiedam, The Netherlands) at a working volume of $1 \mathrm{~L}$. The medium was stirred at $250 \mathrm{rpm}$ and kept at $\mathrm{pH} 6.9 \pm 0.1$ with automatic titration with $4 \mathrm{M} \mathrm{NaOH}$. The medium was continuously stripped with $\mathrm{N}_{2}$ gas containing less than 5 ppm $\mathrm{O}_{2}$ (AGA Gas AB, Sweden) at a rate of $100 \mathrm{~mL} \cdot \mathrm{min}^{-1}$. For xylose, the sparging gas was turned off after inoculation for $4 \mathrm{~h}$ to allow accumulation of $\mathrm{CO}_{2}$ as previously reported [26], which is necessary to promote initial growth. Then, $\mathrm{N}_{2}$ gas was continuously sparged again throughout cultivation. $5 \mathrm{~mL}$ of each culture was taken at specific intervals and spun down to collect supernatant and stored at $-20^{\circ} \mathrm{C}$ until further analysis.

\section{Analytical methods}

Gas samples were taken from the bioreactor's headspace to quantify hydrogen gas and carbon dioxide with gas chromatography using an Agilent 7890B (Santa Clara, CA, USA) equipped with a TCD and a ShinCarbon ST $50 / 80 \mathrm{UM}(2 \mathrm{~m} \times 1 / 16 \times 1 \mathrm{~mm})$ column. Helium gas was fed through the system with a flow rate of $10 \mathrm{~mL} \cdot \mathrm{min}^{-1}$ at $80{ }^{\circ} \mathrm{C}$ for $1 \mathrm{~min}$. The temperature was increased to $100{ }^{\circ} \mathrm{C}$ and held for $4 \mathrm{~min}$ followed by a temperature ramp to $160^{\circ} \mathrm{C}$ for $2 \mathrm{~min}$. The built-in software obtained from Agilent was used for analysis and calculating the percentages of $\mathrm{H}_{2}$ and $\mathrm{CO}_{2}$. The calibration curve of $\mathrm{H}_{2}$ and $\mathrm{CO}_{2}$ were validated after setting up of the $\mathrm{GC}$ and used for analysis afterwards.

Glucose, xylose, and cellobiose were detected on a Shodex SP-0810 column $(8 \times 300 \mathrm{~mm}$, Shodex, Japan $)$ using Milli-Q water as a mobile phase at a flow rate of $0.6 \mathrm{~mL} \cdot \mathrm{min}^{-1}$ at $60{ }^{\circ} \mathrm{C}$. Acetate, lactate, propionate, and ethanol were quantified by high-performance liquid 
chromatography (HPLC; Waters, Milford, MA, USA) equipped with an Aminex HPX-87H ion-exchange column $(7.8 \times 300 \mathrm{~mm}$, Bio-Rad, Hercules, USA). The column was operated at $60^{\circ} \mathrm{C}$ with $5 \mathrm{mM} \mathrm{H}_{2} \mathrm{SO}_{4}$ as a mobile phase at a flow rate of $0.6 \mathrm{~mL} \cdot \mathrm{min}^{-1}$.

\section{Biomass concentration}

An Ultrospec 2100 pro UV/visible spectrophotometer (Amersham Biosciences, UK) was used to determine the optical density (OD) of the culture at $620 \mathrm{~nm}$. A culture volume of $10 \mathrm{~mL}$ was filtrated through a pre-weight Supor-200, 0.2- $\mu \mathrm{m}$ filter (PALL Life Sciences, Mexico) to estimate cell dry weight (CDW). The filters were rinsed thrice with $5 \mathrm{~mL}$ of Milli-Q water and dried in a desiccator overnight. The dry filters were measured on an analytical balance (AG204 DeltaRange, Mettler Toledo, Ohio, USA). The CDW samples were done in duplicate. The correlation between $\mathrm{CDW}$ and $\mathrm{OD}_{620}$ was calculated to estimate CDW of each sample according to:

$$
\mathrm{CDW}=\mathrm{a}[\mathrm{OD}]+\mathrm{b},
$$

where CDW and $b$ are cell dry weight and linear regression constant $\left(\mathrm{g} \cdot \mathrm{L}^{-1}\right)$, respectively. $a$ is a slope of the linear regression. The values for $a$ and $b$ varied with the sugar (combinations) used in the cultures. The equation was obtained as described per [25].

\section{Mathematical modeling to predict $\mu_{\max }$}

The modified Gompertz equation as per Zwietering et al. [27] and optical density (OD) obtained from each case were used for the estimation of $\mu_{\max }$ :

$$
y=A \exp \left\{-\exp \left[\frac{\mu_{\mathrm{m}} \exp }{\mathrm{A}}(\lambda-\mathrm{t})+1\right]\right\},
$$

where $A$ is a term of the asymptotic value, $\mu_{m}$ is the specific growth rate $\left(\mu_{\max }, \mathrm{h}^{-1}\right)$ and $\lambda$ is the length of the lag phase $(h)$.

\section{Inhibition constant $\left(K_{l}\right)$ of glucose and xylose}

The inhibition of glucose uptake by xylose and vice versa is assumed to be based on competitive inhibition of the substrate-binding protein of the $\mathrm{ABC}$ transporter. The two equations that can be derived are:

$$
V_{\mathrm{xyl}}=\frac{V_{m, \mathrm{xyl}} \cdot \frac{X}{\mathrm{~K}_{S, \mathrm{xyl}}}}{1+\frac{X}{K_{\mathrm{S}, \mathrm{xyl}}}+\frac{G}{K_{\mathrm{I}, \mathrm{glu}}}},
$$

and

$$
V_{\mathrm{glu}}=\frac{V_{m, \mathrm{glu}} \cdot \frac{G}{K_{S, \mathrm{glu}}}}{1+\frac{G}{K_{S, \text { glu }}}+\frac{X}{K_{I, \mathrm{xyl}}}},
$$

where $V_{\mathrm{xyl}}$ and $V_{\text {glu }}$ are xylose uptake rate and glucose uptake rate $\left(\mathrm{cmol} \cdot \mathrm{L}^{-1}\right)$, respectively, $V_{\mathrm{m} \text {,xyl }}$ and $V_{\mathrm{m} \text {,glu }}$ are the maximum substrate uptake rate $\left(\mathrm{cmol} \cdot \mathrm{L}^{-1}\right)$. The parameters $X$ and $G$ are the concentration of xylose and glucose $\left(\mathrm{cmol} \cdot \mathrm{L}^{-1}\right)$, respectively.

The aim was to obtain a good appraisal of the inhibition constants for the uptake of xylose $\left(K_{I, \mathrm{glu}}\right)$ and glucose $\left(K_{I, \mathrm{xy}}\right)$ in the cultures of sugar mixtures (Cases D-E). To minimize the number of unknown parameter values, we assumed that the $K_{S}$ value of glucose $\left(K_{S, \text { glu }}\right)$ and xylose $\left(K_{\mathrm{S}, \mathrm{xy}}\right)$ obtained for $C$. saccharolyticus from the previous study [11] was similar to those of $C$. kronotskyensis: the $K_{S, \text { glu }}$ and $K_{S, \text { xyl }}$ being 0.01 and $0.0002 \mathrm{cmol} \cdot \mathrm{L}^{-1}$, respectively. This assumption is adequate as both transporters displayed the same profile of xylose and glucose uptake and $10-20 \%$ change in the $K_{S}$-value had less than $5 \%$ influence on the values of $K_{I, \text { glu }}$ and $K_{I, \text { xyl }}$.

\section{Bioinformatics study related to sugar transporter}

The sugar transporters of C. kronotskyensis related in this study were investigated and compared with those sugar transporters identified in C. saccharolyticus in a previous study [21]. The completed DNA sequences and gene encoding for transporters of C. kronotskyensis (https:// www.ncbi.nlm.nih.gov/nuccore/NC014720) and C. saccharolyticus (https://www.ncbi.nlm.nih.gov/nuccore/ CP000679) are available at the National Center for Biotechnology Information (NCBI; Bethesda, MD, USA). The completed genome sequences of these two species were compared by using Mauve program (Darling lab, University of Technology Sydney).

\section{Acknowledgements}

We acknowledge the financial support from the Ministry of Higher Education, Science, Research and Innovation (Thai Government) and the Swedish Research Council FORMAS to Thitiwut Vongkampang (Project No. 201700795). We also thank Karin Willquist for discussion insight on the kinetic study.

\section{Authors' contributions}

TV wrote the article, planned and performed the experiments. EvN was involved in planning the experiments and writing the article. KS and JE assisted TV in batch fermentations and HPLC analysis. CG coordinated the calculations for kinetic modeling. EvN and CG participated in the discussion of all the results. EvN also critically reviewed the text. All authors have read and approved the manuscript.

\section{Funding}

Open access funding provided by Lund University. This work was supported by the Ministry of Higher Education, Science, Research and Innovation (Thai Government) and the Swedish Research Council FORMAS who did not participate in the execution of the study or in the manuscript writing. 


\section{Available of data and materials}

The datasets during and/or analyzed during the current study are available from the corresponding author on reasonable request.

\section{Declarations}

Ethics approval and consent to participate

Not applicable.

\section{Consent for publication}

Not applicable.

\section{Competing interests}

The authors declare that they have no competing interests.

\section{Author details}

${ }^{1}$ Division of Applied Microbiology, Lund University, P.O. Box 124, 22100 Lund, Sweden. ${ }^{2}$ Division of Biotechnology, Lund University, P.O. Box 124, 221 00 Lund, Sweden.

Received: 18 January 2021 Accepted: 22 March 2021

Published online: 08 April 2021

\section{References}

1. United Nations. Adoption of the Paris Agreement. 2015, http://unfccc.int/ resource/docs/2015/cop21/eng/l09r01.pdf. Accessed 18 Nov 2020.

2. Savla N, Shinde A, Sonawane K, Mekuto L, Chowdhary P, and Pandit S. 17 - Microbial hydrogen production: fundamentals to application, in Microorganisms for Sustainable Environment and Health, Chowdhary $P$, et al., Editors. 2020, Elsevier. p. 343-365. https://doi.org/https://doi.org/10. 1016/B978-0-12-819001-2.00017-6.

3. Pawar SS, van Niel EWJ. Thermophilic biohydrogen production: how far are we? Appl Microbiol Biotechnol. 2013;97(18):7999-8009. https://doi. org/10.1007/s00253-013-5141-1.

4. Vanfossen AL, Lewis DL, Nichols JD, Kelly RM. Polysaccharide degradation and synthesis by extremely thermophilic anaerobes. Ann NY Acad Sci. 2008;1125:322-37. https://doi.org/10.1196/annals.1419.017.

5. Willquist K, Zeidan AA, van Niel EWJ. Physiological characteristics of the extreme thermophile Caldicellulosiruptor saccharolyticus: an efficient hydrogen cell factory. Microb Cell Fact. 2010;9:89. https://doi.org/10. 1186/1475-2859-9-89.

6. Rainey FA, Donnison AM, Janssen PH, Saul D, Rodrigo A, Bergquist PL, et al. Description of Caldicellulosiruptor saccharolyticus gen. nov., sp. nov:: an obligately anaerobic, extremely thermophilic, cellulolytic bacterium. FEMS Microbiol Lett. 1994. https://doi.org/10.1111/j.1574-6968. 1994.tb07043.x

7. van de Werken HJ, Verhaart MR, VanFossen AL, Willquist $K$, Lewis DL, Nichols JD, et al. Hydrogenomics of the extremely thermophilic bacterium Caldicellulosiruptor saccharolyticus. Appl Environ Microbiol. 2008;74(21):6720-9. https://doi.org/10.1128/AEM.00968-08.

8. Chowdhary N, Selvaraj A, KrishnaKumaar L, Kumar GR. Genome Wide ReAnnotation of Caldicellulosiruptor saccharolyticus with New Insights into Genes Involved in Biomass Degradation and Hydrogen Production. PLoS ONE. 2015;10(7):e0133183. https://doi.org/10.1371/journal.pone.0133183.

9. Panagiotopoulos IA, Bakker RR, de Vrije T, Koukios EG, Claassen PAM. Pretreatment of sweet sorghum bagasse for hydrogen production by Caldicellulosiruptor saccharolyticus. Int J Hydrog Energy. 2010;35(15):7738-47. https://doi.org/10.1016/j.ijhydene.2010.05.075.

10. Pawar SS, Nkemka VN, Zeidan AA, Murto M, van Niel EWJ. Biohydrogen production from wheat straw hydrolysate using Caldicellulosiruptor saccharolyticus followed by biogas production in a two-step uncoupled process. Int J Hydrog Energy. 2013;38(22):9121-30. https://doi.org/10. 1016/j.jjhydene.2013.05.075.

11. Bjorkmalm J, Byrne E, van Niel EWJ, Willquist K. A non-linear model of hydrogen production by Caldicellulosiruptor saccharolyticus for diauxiclike consumption of lignocellulosic sugar mixtures. Biotechnol Biofuels. 2018;11:175. https://doi.org/10.1186/s13068-018-1171-3.
12. Miroshnichenko ML, Kublanov IV, Kostrikina NA, Tourova TP, Kolganova TV, Birkeland NK, Bonch-Osmolovskaya EA. Caldicellulosiruptor kronotskyensis sp. nov. and Caldicellulosiruptor hydrothermalis sp. nov., two extremely thermophilic, cellulolytic, anaerobic bacteria from Kamchatka thermal springs. Int J Syst Evol Microbiol. 2008;58(Pt 6):1492-6. https:// doi.org/10.1099/ijs.0.65236-0.

13. Blumer-Schuette SE, Alahuhta M, Conway JM, Lee LL, Zurawski JV, Giannone RJ, et al. Discrete and structurally unique proteins (tāpirins) mediate attachment of extremely thermophilic Caldicellulosiruptor species to cellulose. J Biol Chem. 2015;290(17):10645-56. https://doi.org/10.1074/ jbc.M115.641480.

14. Lee LL, Hart WS, Lunin W, Alahuhta M, Bomble YJ, Himmel ME, et al. Comparative biochemical and structural analysis of novel cellulose binding proteins (Tāpirins) from extremely Thermophilic Caldicellulosiruptor species. Appl Environ Microbiol. 2019. https://doi.org/10.1128/AEM.01983-18.

15. Qiao W, Tang S, Mi S, Jia X, Peng X, Han Y. Biochemical characterization of a novel thermostable GH11 xylanase with CBM6 domain from Caldicellulosiruptor kronotskyensis. J Mol Catal B Enzym. 2014;107:8-16. https:// doi.org/10.1016/j.molcatb.2014.05.009.

16. Jia X, Qiao W, Tian W, Peng X, Mi S, Su H, Han Y. Biochemical characterization of extra- and intracellular endoxylanse from thermophilic bacterium Caldicellulosiruptorkronotskyensis. Sci Rep. 2016;6:21672. https://doi.org/ 10.1038/srep21672.

17. Su H, Qiu W, Kong Q, Mi S, Han Y. Thermostable pectate lyase from Caldicellulosiruptor kronotskyensis provides an efficient addition for plant biomass deconstruction. J Mol Catal B Enzym. 2015;121:104-12. https:// doi.org/10.1016/j.molcatb.2015.08.013.

18. Peng X, Kelly RM, Han Y. Sequential processing with fermentative Caldicellulosiruptor kronotskyensis and chemolithoautotrophic Cupriavidus necator for converting rice straw and $\mathrm{CO}_{2}$ to polyhydroxybutyrate. Biotechnol Bioeng. 2018;115(6):1624-9. https://doi.org/10.1002/bit.26578.

19. Chen $\mathrm{H}$. Chemical composition and structure of natural lignocellulose. In: Chen $\mathrm{H}$, editor. Biotechnology of Lignocellulose: theory and practice. Springer, Netherlands: Dordrecht; 2014. p. 25-71. https://doi.org/10.1007/ 978-94-007-6898-7_2.

20. Chen H. Brief Introduction to the Biotechnology of Lignocellulose. In: Chen $\mathrm{H}$, editor. Biotechnology of lignocellulose: theory and practice. Springer, Netherlands: Dordrecht; 2014. p. 1-24. https://doi.org/10.1007/ 978-94-007-6898-7_1.

21. Vanfossen AL, Verhaart MR, Kengen SM, Kelly RM. Carbohydrate utilization patterns for the extremely thermophilic bacterium Caldicellulosiruptor saccharolyticus reveal broad growth substrate preferences. Appl Environ Microbiol. 2009;75(24):7718-24. https://doi.org/10.1128/AEM.01959-09.

22. Zeidan AA, Van Niel EWJ. Developing a thermophilic hydrogen-producing co-culture for efficient utilization of mixed sugars. Int J Hydrog Energy. 2009;34(10):4524-8. https://doi.org/10.1016/j.jihydene.2008.07.092.

23. Blumer-Schuette SE. Insights into thermophilic plant biomass hydrolysis from Caldicellulosiruptor systems biology. Microorganisms. 2020;8(3):385. https://doi.org/10.3390/microorganisms8030385.

24. Ljunggren M, Willquist K, Zacchi G, van Niel EWJ. A kinetic model for quantitative evaluation of the effect of hydrogen and osmolarity on hydrogen production by Caldicellulosiruptor saccharolyticus. Biotechnol Biofuels. 2011;4(1):31. https://doi.org/10.1186/1754-6834-4-31.

25. Zeidan AA, van Niel EWJ. A quantitative analysis of hydrogen production efficiency of the extreme thermophile Caldicellulosiruptor owensensis $\mathrm{OL}^{\top}$. Int J Hydrog Energy. 2010;35(3):1128-37. https://doi.org/10.1016/j.ijhyd ene.2009.11.082.

26. Willquist K, van Niel EWJ. Growth and hydrogen production characteristics of Caldicellulosiruptor saccharolyticus on chemically defined minimal media. Int J Hydrog Energy. 2012;37(6):4925-9. https://doi.org/10.1016/j. ijhydene.2011.12.055.

27. Zwietering MH, Jongenburger I, Rombouts FM, van 't Riet K. Modeling of the bacterial growth curve. Appl Environ Microbiol. 1990;56(6):875-1881. https://doi.org/10.1128/AEM.56.6.1875-1881.1990.

\section{Publisher's Note}

Springer Nature remains neutral with regard to jurisdictional claims in published maps and institutional affiliations. 